\title{
Double decoupling effectiveness of water consumption and wastewater discharge in China's textile industry based on water footprint theory
}

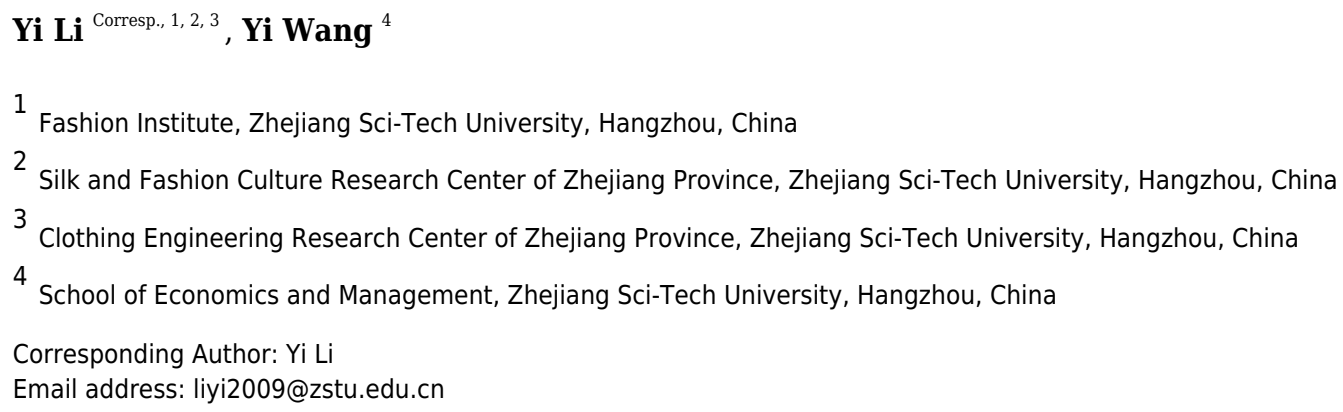

As a traditional pillar industry in China, the textile industry has been intensifying the pressure of water resource load and its reduction of water environment emission over the years. Decoupling water resource consumption and wastewater discharge require decoupling from economic growth to realise the sustainable development of the textile industry. On the basis of water footprint and decoupling theories, this paper analyzed the water consumption decoupling, wastewater discharge decoupling, as well as the double decoupling of water consumption and wastewater discharge of China's textile industry and its three sub-industries (Manufacture of Textile, Manufacture of Textile Wearing and Apparel, Manufacture of Chemistry) from 2001 to 2015. In those years, the sum of the decoupling index in the double-decoupling years is 249 , lower than that in high-decoupling years of water consumption (250) and wastewater discharge (325). Compared with the decoupling of water consumption and of wastewater discharge, the double decoupling is lower, which proves that the conditions for realizing double decoupling are stricter. The double decoupling analysis of water consumption and wastewater discharge, namely, the overall consideration of water resource consumption and water environment pollution, could be used to more effectively promote the realisation of water decoupling in the textile industry. 


\section{Double decoupling effectiveness of water 2 consumption and wastewater discharge in China's 3 textile industry based on water footprint theory}

4

$7 \quad{ }^{1}$ Fashion Institute, Zhejiang Sci-Tech University, Hangzhou, China

$8{ }^{2}$ Silk and Fashion Culture Research Center of Zhejiang Province, Zhejiang Sci-Tech University, 9 Hangzhou, China

\section{Yi Li Corresp., 1, 2, 3, Yi Wang 4}

${ }^{3}$ Clothing Engineering Research Center of Zhejiang Province, Zhejiang Sci-Tech University, Hangzhou, China

${ }^{4}$ School of Economics and Management, Zhejiang Sci-Tech University, Hangzhou, China

Corresponding Author: Yi Li

Email address: liyi2009@zstu.edu.cn

\section{Abstract}

As a traditional pillar industry in China, the textile industry has been intensifying the pressure of water resource load and its reduction of water environment emission over the years. Decoupling water resource consumption and wastewater discharge require decoupling from economic growth to realise the sustainable development of the textile industry. On the basis of water footprint and decoupling theories, this paper analyzed the water consumption decoupling, wastewater discharge decoupling, as well as the double decoupling of water consumption and wastewater discharge of China's textile industry and its three sub-industries (Manufacture of Textile, Manufacture of Textile Wearing and Apparel, Manufacture of Chemistry) from 2001 to 2015. In those years, the sum of the decoupling index in the double-decoupling years is 249 , lower than that in high-decoupling years of water consumption (250) and wastewater discharge (325). Compared with the decoupling of water consumption and of wastewater discharge, the double decoupling is lower, which proves that the conditions for realizing double decoupling are stricter. The double decoupling analysis of water consumption and wastewater discharge, namely, the 
31

32

33

34

35

36

37

38

39

40

41

42

43

44

45

46

47

48

49

50

51

52

53

54

55

56

57

58

59

60

61

62

63

64

65

66

67

overall consideration of water resource consumption and water environment pollution, could be used to more effectively promote the realisation of water decoupling in the textile industry.

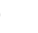

\section{Background}

Water resources per capita in China is $2710 \mathrm{~m}^{3}$, which is less than $1 / 4$ of the world's per capita water resources, ranking 88th in the world. China's water shortage has become a major obstacle to economic and social development(Lv, 2017). At the same time, China's industrial wastewater discharge is relatively large, and the implementation of wastewater treatment measures is not in place, resulting in many wastewater not meeting the professional discharge standards directly into other water bodies, which has brought great pollution to the environment(Wang et al., 2016). In 2015, China's total water consumption was 610.32 billion $\mathrm{m}^{3}$, where industrial water consumption accounted for $21.9 \%$ (Ministry of Water Resources of China, 2015), with 73.53 billion tons of wastewater, $27.1 \%$ of industrial, 22.24 million tons of chemical oxygen demand in wastewater and $13.2 \%$ in industrial wastewater(Ministry of Environmental Protection of the People's Republic of China, 2015).

Textile industry is a traditional pillar industry in China. It has a comparative advantage and an increasing international competitiveness in the international market. China is the world's leading textile producer and exporter. In 2017, China's textile industry exports amounted to 27.455 billion US dollars, accounting for $36.8 \%$ of the world's total textile exports (China National Textile and Apparel Council, 2018). With the rapid development of China's textile industry, the problems of high energy consumption, high water consumption and high emissions seriously restrict the sustainable development of China's textile industry's economy and ecological environment (Wang et al., 2012; Yu et al., 2005; Li et al., 2017). In 2015, textile industry wastewater discharged 1.84 billion tons, ranking third among 41 key industries in China for five consecutive years (2011-2015). In 2015, the textile industry emitted 206 thousand tons of chemical oxygen demand, ranking fourth among 41 key industries in China (Ministry of Environmental Protection of the People's Republic of China, 2011-2015). At the same time, the recycling level of water resources in China's textile industry is on the low side. The water reuse rate in textile industry is less than $70 \%$, which is lower than the average level of $80 \%$ in national industry. The water reuse rate in printing and dyeing industry is only 30\% (China National Textile and Apparel Council, 2018).

Therefore, giving full play to the leading role of textile industry in China's national economy and realizing the green development and sustainable development of textile industry play an important role in constructing Chinese ecological civilization, promoting the development of related industries and stimulating the growth of domestic demand. Environmental protection is not only the responsibility of national environmental management (Tan et al., 2016), but also the responsibility of energy conservation and emission reduction of 
68

69

70

71

72

73

74

75

76

77

78

79

80

81

82

83

84

85

86

87

88

89

90

91

92

93

94

95

96

97

98

99

100

101

102

103

104

105

related industries. According to the textile industry development plan 2016-2020, by 2020, the water intake per textile unit of industrial added value will decrease by $23 \%$, and the total discharge of major pollutants will decrease by $10 \%$. The sustainable development of China's textile industry is facing the dual dilemma of serious water shortage and excessive wastewater discharge. Decoupling is the inevitable choice to break the coupling relationship of Chinese textile industry between economic growth and water resources and environment.

\section{Literature}

Decoupling theory is derived from physical concepts and refers to situations in which the relationship between two or more interrelated variables decreases or ceases to exist ( $\underline{A n g}, B$. W. 2004). The Organization for Economic Co-operation and Development (OECD) defines it as the weakening of the synchronous relationship between economic growth and environmental pressure and sets the ratio of pollution emissions in the final stage to GDP and in the base period as the 'decoupling index', which divided decoupling into absolute and relative (OECD, 2002). Tapio put forward a decoupling elastic model and divided the decoupling relations into several types: weak decoupling, strong decoupling, weak negative decoupling, strong negative decoupling, expansive negative decoupling, recessive decoupling, expansive coupling and recessive coupling (Tapio,2005). The main methods of decoupling evaluation include comprehensive analysis of variation, decoupling index, elastic analysis and decoupling analysis based on complete decomposition technology, IPAT model, descriptive statistical analysis, econometric analysis and differential regression coefficient (Zhong et al., 2010). Moreover, the coupling relationship between economic development and environmental pressure increases the difficulty of reducing global emissions, and the effective use of water resources is extremely important to promote economic development (Azad et al., 2015). The decoupling method has been used extensively in research on water resources and environment, mostly from the perspectives of decoupling of water resource consumption and economic growth, as well as the decoupling of wastewater discharge and economic growth.

In the field of water consumption decoupling, Lesin et al. (2016) obtained the decoupling relationship between economic growth and water consumption by discussing the reasons why water pollution supports the weak regional economic growth. Wang (2015) applied decoupling theory and Tapio elasticity analysis to analyze the relationship between China's economic growth and water resource utilisation from the perspective of time and space and concluded that the decoupling between industrial production and industrial water use was weaker than that in agriculture. Li et al. (2017) analyzed the decoupling elasticity of water consumption and economic growth of the textile industry and its three sub-industries and concluded that the scale factor of the textile industry drove water resource consumption and that the efficiency factor inhibited the increase of total water resource consumption. In addition, the decoupling theory of water resources could also be used to predict the decoupling status of resources and economic 
106

107

108

109

110

111

112

113

114

115

116

117

118

119

120

121

122

123

124

125

126

127

128

129

130

131

132

133

134

135

136

137

138

139

140

141

142

143

144

145

development in the future. Wu (2014) predicted that China's economic development and water resources utilisation would be absolutely decoupled by 2020 through the establishment of a decoupling analysis model. Gilmont (2015) used the decoupling theory to discuss the decoupling relationship between the virtual water flow of international food trade and the tonnage of food imports and corroborated that trade reduced the blue water footprint. By discussing the decoupling practice between economic development and resource consumption, Zhou et al. (2014) put forward policy suggestions focusing on the real economy for China to achieve sustainable and stable economic growth. Similarly, on the basis of decoupling theory, Lesin et al. (2017) innovated the management method of water resources in Russia.

In the field of wastewater discharge decoupling, Wang (2013) used the decoupling index to analyze the decoupling relationship between water environment pollution and economic growth in China's textile industry. The paper concluded that the grey water footprint of China's textile industry shows a trend of strong decoupling (Wang, 2013). Li et al. (2016) analyzed the decoupling status between water environmental pressure and economic growth in China from 1991 to 2013, taking industrial wastewater discharge as the index of water environmental pressure. The paper affirmed that technological effect had no significant impact on environmental regulation and that the structural and scale effects had a significant impact ( $L i$ et al., 2016). Zhang et al. (2014) showed a weak decoupling relationship existed between agricultural water environment and crop yield. Li et al. (2018) used the textile industry as an example to analyze the decoupling elasticity and contended that the scale factor was the largest contributor to promote wastewater discharge and that the efficiency and structure factors were the driving forces for wastewater reduction. Yu et al. (2013) combined the trend of China's ecological efficiency development and the reasons for its dynamic change. China's resource utilisation, energy consumption and wastewater discharge were relatively decoupled from its economic development from 1978 to 2010 and absolutely decoupled from economic growth in terms of smoke and dust emission, chemical oxygen demand and ammonia nitrogen. Moreover, on the basis of the wastewater discharge decoupling study, reducing the discharge of industrial wastewater is the key to reducing the industrial gray water footprint, protecting the water environment and building the sustainable development of the industrial economy (Ban et al., 2017).

In actual industrial production and ecological economic system, the water consumption, wastewater emission and economic development comprise a whole system. Only one aspect of decoupling between water resource consumption and economic growth, or between water environment discharge and economic growth, would neglect the systematic integrity of resources, environment and economy, and the results would not be comprehensive. The premise of realizing sustainable industry development is the decoupling of economic growth from water resource consumption and from wastewater discharge, that is, the double decoupling of water consumption and wastewater discharge (Li et al., 2017). Lu et al. (2011) deduced resource decoupling and emission decoupling indexes from the IGT and $\mathrm{I}_{\mathrm{e}} \mathrm{GTX}$ equations, respectively. According to the decoupling index, the decoupling degree of resource consumption, waste 
146

147

148

149

150

151

152

153

154

155

156

157

158

159

160

161

162

163

164

165

166

167

168

169

170

171

172

173

174

175

176

177

178

179

180

181

182

183

emissions, and GDP is divided into three levels: absolute decoupling, relative decoupling and undecoupling. Through empirical analysis, developing countries with rapid economic growth were concluded to be less likely to obtain a higher decoupling index than developed countries with slower economic growth. Gai et al. (2013) analyzed the decoupling status of the resource consumption, environmental pollution and economic development of 16 cities in the Yangtze River Delta region from 2000 to 2009 and found differences in time as well as indicators between resource consumption, environmental pressure and the decoupling degree of comprehensive resource and environment. Another paper calculated the blue water, gray water, and water footprints of China's textile industry from 2001 to 2014 but mainly analyzed the factors and contributions that affected the water footprint (Li et al., 2017). The effectiveness of single decoupling of water resource consumption and wastewater discharge, as well as double decoupling of water consumption and wastewater discharge, were not compared.

On the basis of the above research, the development of the textile industry is restricted by water resources and the water environment. Research on single water consumption decoupling or single wastewater discharge decoupling showed defects. Thus, the double decoupling problem of water consumption and wastewater discharge requires further attention. We introduce decoupling indices, assign a value to the degree of decoupling, and compare their effectiveness(Guo et al., 2013). Taking China's textile industry as an example, the present study further explores the relationship between the double decoupling of water consumption and wastewater discharge and the single decoupling of the water consumption or wastewater discharge. Water footprint was used to characterise the water resources environment, and the decoupling relationship between water resources environment and economic growth was obtained by using the Tapio elastic analysis method. For the further exploration of the internal mechanism of water decoupling and for putting forward of countermeasures and suggestions, the validity of the results of water consumption decoupling (blue water footprint decoupling), wastewater discharge decoupling (gray water footprint decoupling) and double decoupling of water consumption and wastewater discharge (water footprint decoupling) were analyzed and compared by using the assignment partition method.

\section{Methods and Data}

\subsection{Water Footprint Accounting Method of the Textile Industry}

Water footprint includes blue water, green water, and grey water footprints. In the textile industry production, blue water footprint refers to the consumed surface water or groundwater resources. Green water footprint refers to the total amount of consumed water from rainwater, soil, and air. Given its small consumption amount in China's textile industry, green water footprint is excluded in this research. Grey water footprint refers to the amount of water needed to accommodate the pollutants produced in the production process. Blue water footprint calculation directly takes the textile industry water resource consumption. Grey water footprint 
184

185

186

187

188

189

190

191

192

193

194

195

196

197

198

199

200

201

202

203

204

205

206

207

208

209

210

211

212

213

214

215

216

217

218

219

accounting refers to the total amount of fresh water required for the absorption and assimilation of pollutants by natural background concentration and existing water quality environment before the treatment of textile industry wastewater.

The specific formulas are as follows:

$$
\begin{aligned}
& W F=W F_{b}+W F_{g y}, \\
& W F_{b}=W_{u}, \\
& W F_{g y}=\max \left[\frac{L[k]}{C_{s}[k]-C_{n}[k]}\right] .
\end{aligned}
$$

In equations (1), (2) and (3), WF is water footprint; $W F_{b}$ is blue water footprint; $W F_{g y}$ is grey water footprint and $W_{u}$ is the total water consumption of the textile industry. All units are in million tons (Mt). $L[k]$ is the amount of pollutant $k$ in the waste water discharged by the textile industry; $C s[k]$ is the concentration limit value of pollutant $k$ stipulated in the pollutant emission standard and $C n[k]$ is the background concentration of pollutant $k$ in natural water body. These units are in million tons of pollutant/year, with $C n[k]$ assumed to be 0 million tons of pollutant/year.

Table 1 shows the calculation formula of the water footprint. The calculation standard of the concentration limit of pollutant $\mathrm{k}$ stipulated in the pollutant discharge standard adopts the relevant stipulation of the water pollutant discharge limit value of existing enterprises in the Textile Dyeing and Finishing Industry (GB13458-2013) (Ministry of Environmental Protection of China, 2013). The concentrations of chemical oxygen demand $\left(\mathrm{COD}_{\mathrm{Cr}}\right)$, biological oxygen demand $\left(\mathrm{BOD}_{5}\right)$, suspended solids, ammonia nitrogen and other water pollutants in natural water are extremely low. In addition, the natural concentrations of these pollutants in different parts of the water body vary significantly. As such, collecting accurate data of these pollutant indicators is difficult. This paper assumes that $C_{n}[k]$ is 0 , which means that the grey water footprint value will be slightly smaller. When calculating the grey water footprint of the textile industry, the value according to $\mathrm{COD}_{\mathrm{Cr}}$ is the largest.

Table 1. Emission limits for wastewater pollutants in the textile industry. Unit: mg/L. (Ministry of Environmental Protection of China, 2013.)

\subsection{Decoupling Theory}

The decoupling accounting method adopted in this paper is based on the decoupling elasticity method proposed by Tapio (2005). The main accounting index is the decoupling elasticity coefficient, which is defined as the ratio between resource consumption or environmental pressure change rate and economic change rate in a certain period of time. The formula is as follows:

$$
D=\frac{\% \Delta V O L}{\% \Delta G}=\frac{\left(V O L_{t}-V O L_{t-1}\right) / V O L_{t-1}}{\left(G_{t}-G_{t-1}\right) / G_{t-1}}
$$

In formula (4), $D$ is the elastic coefficient; $V O L_{t}$ and $V O L_{t-1}$ are the resource consumption or environmental pressure in the $t$ year and $t-1$ year, respectively; $G_{t}$ and $G_{t-1}$ are the GDP in the $t$

Peer) reviewing PDF | (2019:01:34324:1:1:NEW 23 Mar 2019) 
220

221

222

223

224

225

226

227

228

229

230

231

232

233

234

235

236

237

238

239

240

241

242

243

244

245

246

247

248

249

250

251

252

253

254

255

256

year and $t-1$ year, respectively; $\% \triangle V O L$ is the growth rate of resource consumption or environmental pressure and $\% \Delta G$ is the economic growth rate. The decoupling state is divided into eight types. Figure 1 shows that strong decoupling is the most ideal state of sustainable development, followed by weak decoupling. In addition, the other states are all not ideal, and the strong and negative decoupling is the most unsatisfactory state.

\section{Figure 1. Decoupling standard of Decoupling Elasticity Method}

\subsubsection{Improvement of decoupling model based on water footprint}

The water footprint of the textile industry shows the double effect of water consumption and wastewater discharge. The double decoupling of these two factors is the decoupling relationship between the water footprint of the textile industry $(W F)$ and the total output value of the textile industry $(G)$. In this paper, the decoupling elasticity method is adopted to define $D_{G-W F}$ as the decoupling elasticity index between the water footprint and the economic growth of the textile industry. The decoupling state is calculated as the elasticity index. The formula is as follows:

$$
D_{G-W F}=\frac{\% \Delta W F}{\% \Delta G}=\frac{\%\left(W F^{t}-W F^{t-1}\right) G^{t-1}}{\%\left(G^{t}-G^{t-1}\right) W F^{t-1}} .
$$

In formula (5), $W F^{t}$ and $W F^{t-1}$ represent the water footprint of the textile industry in $t$ year and $t-1$ year, respectively. The water footprint growth rate of the textile industry and the growth rate of the total industrial output value of the textile industry can be obtained by calculating the corresponding data of the two time points.

\subsubsection{Assignment of decoupling degree}

According to Tapio's deepening decoupling index, the decoupling status between water footprint and economic growth of the textile industry is summarised into eight types. The decoupling results of water consumption, wastewater discharge and the double decoupling of water consumption and wastewater discharge are analyzed and compared to intuitively understand the change of the decoupling state. First, the decoupling states are divided into several intervals and then ranked according to the advantages and disadvantages of decoupling states. Finally, decoupling elastic coefficients of each interval are assigned from 1 to 28(Guo et al., 2013). The larger decoupling index shows better decoupling state between the water footprint and economic growth of the textile industry. Table 2 shows the divisions.

\section{Table 2. Standard of Double Decoupling Degree of Water Consumption} and Wastewater Discharge in the Textile Industry

\subsection{Data}

According to China's National Economic Industry Classification (GB/T 4754-2011) (National Bureau of Statistics of the People 's Republic of China, 2011), the textile industry's gross industrial product and total wastewater discharge are regarded as the sum of data of three sub-industries: Manufacture of Textile (MT); Manufacture of Textile Wearing and Apparel (MTWA); and Manufacture of Chemical Fibers (MCF). With 2001-2014 as the research interval, the total output value of the textile industry (converted to constant price in 2014), total 
257

258

259

260

261

262

263

264

265

266

267

268

269

270

271

272

273

274

275

276

277

278

279

280

281

282

283

284

285

286

287

288

289

290

291

292

293

water consumption and pollutant content of wastewater used by the research institute are included in the China Environmental Yearbook (Ministry of Environmental Protection of the People's Republic of China, 2002-2006) and China Environmental Statistics Annual Report (Ministry of Environmental Protection of the People's Republic of China, 2006-2014). However, given the misprints in the industrial water consumption data of MCF in 2012, this paper selected the average value of data in 2011 and 2013 as replacement.

\section{Results and Discussion}

\subsection{Results and Analysis of Water Footprint Decoupling in the Textile Industry 3.1.1 Blue water footprint (water consumption) decoupling}

Table 3 shows the calculation results of the decoupling elasticity of China's textile industry from 2002 to 2015 . Except for 2002-2004 and 2014, the growth rate of water resource consumption in the textile industry is less than its economic growth rate. Except for 2012, the economic output of the textile industry showed positive growth in other years. In the sample period, the growth rate of water resources consumption decreased for seven years .

Table 3. Decoupling Elasticity Index of Water Resources Consumption in China's Textile Industry from 2002 to 2015

Data Sources: $\% \triangle W C$ is the growth rate of water consumption; $\% \Delta G$ is the economic growth rate; and $D_{G-W C}$ is the decoupling elasticity of water consumption and economic growth.

Table 3 shows that the decoupling state during the Tenth Five-Year Plan period (20012005) is unstable but improved in the Eleventh Five-Year Plan period (2006-2010). During the Twelfth Five-Year Plan period (2011-2015), decoupling is relatively good, but unstable. In terms of strong decoupling, only the decoupling elasticity in 2003 is an absolute value at 1.32 whereas the other values are less than 1 . However, the degree of decoupling is weak and needs further improvement. In particular, the most unsatisfactory state of decoupling is in 2012 with a strong negative decoupling, which is closely related to the increase of water consumption and economic recession in that year. In 2014, the decoupling elasticity reached its maximum value of 13.47 in the sample period. The total industrial water consumption in that year increased considerably, resulting in a rebound between the economic development of the textile industry and resource consumption.

\subsubsection{Grey water footprint (wastewater discharge) decoupling}

Table 4 shows the decoupling elastic calculation results of the grey water footprint of the textile industry and economic growth in China from 2002 to 2015.

Table 4. Decoupling Elasticity of Grey Water Footprint

in China Textile Industry from 2002 to 2015

Data Sources: $\% \triangle W F_{g}$ is the growth rate of wastewater discharge; $\% \Delta G$ is the economic growth rate; and $D_{G-W F g}$ is the decoupling elasticity of wastewater discharge and economic growth. 
294

295

296

297

298

299

300

301

302

303

304

305

306

307

308

309

310

311

312

313

314

315

316

317

318

319

320

321

322

323

324

325

326

327

328

329

330

331

332

333

From the overall decoupling trend, China's textile industry economic growth and gray water footprint shows a good decoupling. Apart from the negative economic growth rate of the textile industry in 2012 that led to the recession decoupling, the other years mainly showed strong or weak decoupling, with the overall trend showing an increasing decoupling. Specifically, the decoupling trend can be divided into three stages.

From 2002 to 2003, the gray water footprint and economic growth achieved strong decoupling for two consecutive years. The decoupling status was ideal. The textile industry's economic growth rate remained approximately $7 \%$, whereas the reduction rate of grey water footprint exceeded 5\%. From 2004 to 2007, the gray water footprint of the textile industry and economic growth showed a weak decoupling state for four consecutive years. Moreover, the gross industrial output value of China's textile industry continued growing at a relatively high speed. The growth rate of grey water footprint is also positive, which shows no absolute reduction at this stage. From 2008 to 2012, although the total industrial output value of the textile industry keeps rising, the growth rate of grey water footprint alternates positively and negatively, resulting in a strong and weak oscillating decoupling state. In 2012, a state of recession decoupling occurred as the grey water footprint of the textile industry achieved negative growth, and the economic growth rate was negative. These scenarios show that, although the textile industry has not fully realised the production of zero pollution in the water environment, the trend of decoupling between the two is increasing. From 2013 to 2015, the grey water footprint reduced in absolute terms, whilst the economy is growing, resulting in a strong decoupling.

\subsubsection{Double decoupling of water consumption and wastewater discharge}

Table 5 exhibits the decoupling elasticity calculation results of water footprint and economic growth of China's textile industry from 2002 to 2015.

\section{Table 5. Decoupling elasticity of water resources environment and economic growth} in China's textile industry from 2002 to 2015

Data Sources: $\% \triangle W F$ is the growth rate of water footprint; $\% \Delta G$ is the economic growth rate; and $D_{G-W F}$ is the decoupling elasticity of water footprint and economic growth.

From the overall decoupling trend, the decoupling trend between China's textile industry water footprint and economic growth is good. From the change of decoupling states, it can be divided into three stages.

From 2002 to 2004, the decoupling between water footprint and economic growth is unstable, alternating between expansive coupling and strong decoupling. From 2005 to 2011, the decoupling of water footprint and economic growth improved. Although the development of China's textile industry has not yet gained independence from the water footprint, the negative impact of economic development on water environment decreased. From 2012 to 2015, strong decoupling and negative decoupling alternated between the water footprint and the industry's economy. For the first time, the growth rate of water footprint in 2014 exceeded the growth rate of total output value of textile industry. The elasticity coefficient was 5.28, showing a state of negative expansion decoupling, and the decoupling status was not optimistic. Given the change of the water footprint, this is due to the rapid growth of water resources consumption in textile 
334 industry in 2014, as well as the rebound of economic development, water resources consumption

335

336

337

338

339

340

341

342

343

344

345

346

347

348

349

350

351

352

353

354

355

356

357

358

359

360

361

362

363

364

365

366

367

368

369

370

371

372

373

374

and water environmental pollution.

\subsection{Comparative study on the effectiveness of decoupling results}

In the present study, the results of water consumption decoupling, wastewater discharge decoupling and the double decoupling of water consumption and wastewater discharge in China's textile industry from 2002 to 2015 are sorted and summarised. The effectiveness of the three decoupling types is compared with the absolute number and decoupling index of the decoupling years. On the whole, the double decoupling of water consumption and wastewater discharge in China's textile industry is the most unsatisfactory due to the simultaneous decoupling of water consumption and wastewater discharge impact. The increase of water resource consumption in a certain year or the increase of pollutant discharge in wastewater both lead to the deterioration of decoupling in that year.

\subsubsection{Absolute number comparison of decoupling years}

Table 6 compares the results of water consumption decoupling, wastewater discharge decoupling and the double decoupling of water consumption and wastewater discharge in China's textile industry from 2002 to 2015.

In terms of the number of years to achieve decoupling, the decoupling of wastewater discharge reached 13 years, and only 2012 showed the recession decoupling. However, both water consumption decoupling and wastewater discharge decoupling indices failed to reach the decoupling index for 4 years. From the absolute number of strong decoupling years, the decoupling of water consumption is 7 years, the decoupling of wastewater discharge is 7 years, and the double decoupling of water consumption and wastewater discharge is only 6 years. In these 6 years, the absolute value of decoupling elasticity coefficient in 2 years is less than 0.1 . Especially in 2006 , the elasticity coefficient is -0.003 , which has approached the critical value of strong decoupling and weak decoupling. In terms of the number of weak decoupling years, water consumption decoupled for 3 years, wastewater discharge decoupled for 6 years, and finally double decoupling of water consumption and wastewater discharge occurred for 4 years.

\section{Table 6. Absolute number comparison of decoupling years}

\subsubsection{Decoupling index comparison}

Each decoupling state is ranked and assigned to further quantify the performance of the three types of decoupling in the textile industry during the sample period. The decoupling index for evaluating the three types of decoupling state is then obtained. Figure 2 shows the decoupling index comparison of the three results.

\section{Figure 2. Decoupling index comparison}

In terms of the number of years to achieve strong decoupling, the total number of decoupling indices for strong decoupling years in water consumption decoupling is 184 . The total number of decoupling indices for strong decoupling years in wastewater discharge decoupling is 190. The total number of decoupling indices for strong decoupling years in double decoupling of water consumption and wastewater discharge is only 158, which is much lower than the other two decoupling types. Combined with the situation of the weak decoupling years, the sum of the strong and the weak decoupling indices of the double decoupling of water consumption and

Peer) reviewing PDF | (2019:01:34324:1:1:NEW 23 Mar 2019) 
375 wastewater discharge is the lowest, only 249.The sum of the strong and weak decoupling indices 376 of water consumption decoupling and wastewater discharge decoupling reached 250 and 325, 377 respectively. The result shows that despite the optimistic results on the number of years 378 necessary for the textile industry to achieve double decoupling of water consumption and

379 380

381

382

383

384

385

386

387

388

389

390

391

392

393

394

395

396

397

398

399

400

401

402

403

404

405

406

407

408

409

410

411

412 wastewater discharge, its decoupling index is not ideal within the decoupling range.

According to the above analysis, whether from the perspective of absolute number of decoupling years or from the perspective of decoupling index, the requirement of double decoupling of water consumption and wastewater discharge is more stringent than the single water consumption decoupling or the wastewater discharge decoupling. One reason is that the double decoupling of water consumption and wastewater discharge computes for the economic system and the water resource consumption and wastewater discharge at the same time. Regardless of which aspect of the data is not ideal, decoupling will not occur. Water consumption and wastewater discharge require reduction to enhance the environmental effect of industrial water resources. Therefore, the double decoupling of water consumption and wastewater discharge from the comprehensive perspective of resources and environment is of higher reference significance.

The comparison of decoupling effectiveness is based on the current situation of China's industrial water management. When formulating industrial water management policies, China lacks innovation of water management mode for the whole life cycle of industrial production and total water footprint control in industrial production process due to the over-detailed division of labor among departments or the existence of rights barriers. In the newer documents, the total amount of water intake is limited by the Measures for the Administration of Water Intake Permit issued by the Ministry of Water Resources of China (revised in 2017); the Water Pollution Prevention and Control Law of the People's Republic of China (2017) stipulates the total amount of wastewater discharge; and the Technical Guidelines for the Drafting of National Water Pollutant Discharge Standards (HJ 945.2-2018) issued by the Ministry of Ecological Environment of China (2018) directly affects industrial wastewater. The direct and indirect emission limits are specified. In 2013, although the General Office of the State Council of China "Implementing the Strictest Assessment Measures for Water Resources Management System" strengthened the management at both ends. It stipulated the total water intake control target, water intake efficiency target and water quality control target, but there is still a lack of management means for the whole life cycle.

\section{Conclusions and Suggestions}

On the basis of the theory of water footprint decoupling, this paper makes a comparative analysis of water consumption decoupling, wastewater discharge decoupling and double decoupling of water consumption and wastewater discharge in China's textile industry and its sub-industries from 2001 to 2015 . The main conclusions are as follows: 
413

414

415

416

417

418

419

420

421

422

423

424

425

426

427

428

429

430

431

432

433

434

435

436

437

438

439

440

441

442

443

444

445

446

447

448

449

450

451

452

1. Water consumption decoupling and wastewater discharge decoupling in China's textile industry are higher. Amongst the 14 calculation results from 2002 to 2015, according to water consumption decoupling, seven years show strong decoupling (2003, 2006, 2008, 2009, 2011, $2013,2015)$, and three years show weak decoupling $(2005,2007,2010)$. According to wastewater discharge decoupling, seven years show strong decoupling $(2002,2003,2008,2010$, $2013,2014,2015)$ and six years show weak decoupling $(2004,2005,2006,2007,2009,2011)$. With the rapid expansion of China's textile economy, the progress of water saving and emission reduction technology and the higher level of enterprise management have improved the resource and environmental effects of industrial production.

2. The double decoupling of water consumption and wastewater discharge in China's textile industry shows alternating results although the overall decoupling status is good. The types of decoupling between economic growth of textile industry and water consumption and wastewater discharge in China include strong decoupling, weak decoupling, expansion coupling, weak negative decoupling and expansion negative decoupling. Amongst the 14 calculation results, six years show strong decoupling $(2003,2006,2008,2011,2013,2015)$, and four years show weak decoupling $(2005,2007,2009,2010)$. On the whole, the double decoupling of water consumption and wastewater discharge of textile industry is higher, but the economic development of textile industry has not achieved complete independence from the water footprint.

3. The double decoupling of water consumption and wastewater discharge is more effective than single water consumption decoupling or single wastewater discharge decoupling. In terms of the number of years needed to achieve double decoupling of water consumption and wastewater discharge, ten years showed double decoupling, with six years for strong decoupling and four years for weak decoupling. Compared with water consumption decoupling and wastewater discharge decoupling, the double decoupling result is lower. In terms of the decoupling index in the decoupling years, the sum obtained in the double-decoupling years was 249 , lower than that in the high-decoupling years of water consumption (250) and wastewater discharge (325). Generally, the double decoupling of water consumption and wastewater discharge in China's textile industry is not optimistic compared with single water consumption decoupling and single wastewater discharge decoupling. This scenario verifies that the conditions for achieving the double decoupling of water consumption and wastewater discharge are more stringent, which means a higher reference significance for improving the management level of water resources.

The double decoupling of water consumption and wastewater discharge is an inevitable choice for the sustainable development of the textile industry. Promoting comprehensive water resource saving and recycling and enhancing the level of the comprehensive utilisation of water resources need green developments. Textile industry should carry out the life cycle water use management, issue the total water resources control and the total wastewater discharge control policy, and enforce the water footprint evaluation standard of the textile 
453 industrial park, textile enterprises and the textile products. A green industrial park, green 454 products, green enterprises, optimised green supply chain, green institutional innovation, and 455 others could be comprehensively advanced. These measures could realise water metering 456 type management innovation, improve the efficiency of structural water production, 457 strengthen the effect of water management in enterprises, promote intensive water 458 management ability and reduce the absolute amount for water and wastewater discharge. 459 Thus, the textile industry could become the leading example of consumption reduction and 460 water resource saving.

461

462

\section{Reference}

Lv R. 2017. The protection of water resources in China. Heihe Journal(01):1-3.

Wang Y, Chen Y. 2016. Pollution Status and Control Analysis of Industrial Wastewater. Resources Economization \& Environmental Protection(11):37.

Ministry of Water Resources of the People's Republic of China. 2015. China Water Resources Bulletin. Available online: http://www.mwr.gov.cn/sj/tjgb/szygb/201612/t20161229783348.html(accessed on 7 March 2019).

Ministry of Environmental Protection of the People's Republic of China. 2015. Annual Statistic Report on Environment in China. Beijing: China Environmental Science Press.

China National Textile And Apparel Council. 2018. China Textile Industry Development Report. Beijing: China Textile \& Apparel Press.

Wang LL, Wu XY, Ding XM, Wang LH, Yu JM. 2012. Case Study on Industrial Carbon Footprint and Industrial Water Footprint of Cotton Knits. Dyeing \& Finishing 38(07):43-46 .

Yu YZ, Xi DL, Zhu JJ, Gong JL. 2005. Strategy on the treatment of waste water from the textile industry of China. Journal of Textile Research (06):145-148.

Li Y, Shi RJ, Luo Y, Wang LL. 2017. Analysis of peak carbon emissions simulation and influencing factors in textile industry: A case study in Ningbo. Silk 54, 36-42.

Ministry of Environmental Protection of the People's Republic of China. 2011. Annual Statistic Report on Environment in China. Beijing: China Environmental Science Press.

Ministry of Environmental Protection of the People's Republic of China. 2012. Annual Statistic Report on Environment in China. Beijing: China Environmental Science Press.

Ministry of Environmental Protection of the People's Republic of China. 2013. Annual Statistic Report on Environment in China. Beijing: China Environmental Science Press. 
486 Ministry of Environmental Protection of the People's Republic of China. 2014. Annual Statistic 487 Report on Environment in China. Beijing: China Environmental Science Press.

488 Yujing Tan \& Kai Fang (2016) Environmental Governance in China, Journal of Chinese Governance, 1:1, 191-194, DOI: 10.1080/23812346.2016.1138707.

490

491

492

493

494

495

496

497

498

499

500

501

502

503

504

505

506

507

508

509

510

511

512

513

514

515

516

517

518

519

520

521

522

523

524

525

Ang, B. W.. 2004. Decomposition Analysis For Policymaking In Energy: Which Is The Preferred Method? Energy Policy 32(9): 1131-1139.

OECD-Organization for Economic Co-operation and Development. 2002. Indicators to Measure Decoupling of Environmental Pressure from Economic Growth. Sustainable Development. SG/SD 1/Final.

Website: http://www.olis.oecd.org/olis/2002doc.nsf/LinkTo/sg-sd(2002)1-final accessed on August 28, 2010.

Tapio, P. 2005. Towards a theory of decoupling: degrees of decoupling in the EU and case of road traffic in Finland between 1970 and 2001. Transport Policy. 12, 137-151.

Zhong LY, Huang XJ, Han L, Wang BY. 2010. Review on the Research of Decoupling Analysis in the Field of Environments and Resource. Journal of Natural Resources 25(8) : 1400 - 1412.

Azad M, Ancev T \& Hernández-Sancho F. 2015. Efficient Water Use for Sustainable Irrigation Industry. Water Resources Management vol. 29, no. 5, pp. 1683-1696.

Lesin, Y. V. , Fedulova, E. A., Akulov, A. O., Vik, S. V. , \& Korchagin, R. L. . 2016. Water resources management in support of raw region based on decoupling effect. Social Science Electronic Publishing.

Wang BQ. 2015. Study on the relationship between Chinese economic growth and water resources based on the decoupling analysis. Lanzhou University.

Li Y, Luo Y, Wang YZ, Wang LL, Shen MH. 2017. Decomposing the Decoupling of Water Consumption and Economic Growth in China's Textile Industry. Sustainability 2017, 9(3):412.

Wu D. 2014. Evaluation and Prospect on the Decoupling Trend of Economic Development and Water Resource Utilization in China. Journal of Natural Resources (1):46-54.

Gilmont, M. 2015. Water resource decoupling in the mena through food trade as a mechanism for circumventing national water scarcity. Food Security, 7, 1-19.

Zhou GM, Li X, Zhou Y. 2014. Enlightenment of decoupling policy of international economic development from resources and environment to China. Environmental Protection 42(06):6466.

Lesin Y. V. , Fedulova E. A., Akulov A. O., Vik S. V. , \& Korchagin R. L. . 2017. Water resources management in support of raw region based on decoupling effect. IOP Conference Series: Earth and Environmental Science, 50, 012026.

Wang LL. 2013. Research and Demonstration of Carbon Footprint and Water Footprint of Textiles and Clothing. Shanghai: Donghua University.

Li N, Sun T. 2016. Environmental Regulation, Water Environmental Pressure and Economic Growth_Based on the Decomposition of Tapio Decoulping Elasticity. Science and Technology Management Research 36(4):258-262.

Zhang Y, Yang QS. 2014. Decoupling agricultural water consumption and environmental impact

Peer) reviewing PDF | (2019:01:34324:1:1:NEW 23 Mar 2019) 
526

527

528

529

530

531

532

533

534

535

536

537

538

539

540

541

542

543

544

545

546

547

548

549

550

551

552

553

554

555

556

557

558

559

560

561

562

563

564

565

from crop production based on the water footprint method: a case study for the heilongjiang land reclamation area. Ecological Indicators, 43, 29-35.

Li Y, Shen J, Lu LL, Luo Y, Wang LL, Shen MH. 2018. Water environmental stress, rebound effect, and economic growth of China's textile industry. Peerj, 6.

Yu YD, Chen DJ, Zhu B, Hu SY. 2013. Eco-efficiency trends in china, 1978-2010: decoupling environmental pressure from economic growth. Ecological Indicators, 24(1), 177-184.

Ban RB, Zhang L, Cao YJ. 2017. Analysis of Cooperative Development Between Water Environment and Industrial Economy Growth in Anshun City Based on Grey Water Footprint. Water Resources and Power 35(06): 120-123.

Li Y, Lu LL, Tan YX, Wang LL, Shen MH. 2017. Decoupling Water Consumption and Environmental Impact on Textile Industry by Using Water Footprint Method: A Case Study in China. Water 9(2):124.

Lu ZW, Wang HM, Yue Q. 2011. Decoupling Indicators: Quantitative Relationships between Resource Use, Waste Emission and Economic Growth. Resources Science 33(1).

Gai M, Hu HA, Ke LN. 2013. Decoupling Analysis between Economic Development and Resources and Environmental of the Yangtze River Delta. Journal of Natural Resources 28(02):185-198.

Guo CL, Zhang ZG. 2013. Evaluation Research on Decoupling of Pollutant Emission Growth and Economic Growth. Areal Research and Development 32(3), 94-98.

Ministry of Environmental Protection of China.2012. Discharge Standard of Water Pollutant for Dyeing and Finishing of Textile Industry (GB 4287-2012). Available online:http://kjs.mep.gov.cn/hjbhbz/bzwb/shjbh/swrwpfbz/201211/t20121109_241788.htm (accessed on 8 September 2016).

National Bureau of Statistics of the People's Republic of China. 2011.China's National Economic Industry Classification Standard (GB/T4754-2011). Available online:http://www.mca.gov.cn/article/sj/tjbz/b/201507/20150700854769.shtml (accessed on 29 October 2016).

Ministry of Environmental Protection of the People's Republic of China. 2002-2006. China's Environmental Yearbook. Beijing: China Environmental Science Press.

Ministry of Environmental Protection of the People's Republic of China. 2006. Annual Statistic Report on Environment in China in 2006. Beijing: China Environment Press.

Ministry of Environmental Protection of the People's Republic of China. 2007. Annual Statistic Report on Environment in China in 2007. Beijing: China Environment Press.

Ministry of Environmental Protection of the People's Republic of China. 2008. Annual Statistic Report on Environment in China in 2008. Beijing: China Environment Press.

Ministry of Environmental Protection of the People's Republic of China. 2009. Annual Statistic Report on Environment in China in 2009. Beijing: China Environment Press.

Ministry of Environmental Protection of the People's Republic of China. 2010. Annual Statistic Report on Environment in China in 2010. Beijing: China Environment Press.

Ministry of Environmental Protection of the People's Republic of China. 2011. Annual Statistic

Peer) reviewing PDF | (2019:01:34324:1:1:NEW 23 Mar 2019) 
566 Report on Environment in China in 2011. Beijing: China Environment Press.

567 Ministry of Environmental Protection of the People's Republic of China. 2012. Annual Statistic 568 Report on Environment in China in 2012. Beijing: China Environment Press.

569 Ministry of Environmental Protection of the People's Republic of China. 2013. Annual Statistic 570 Report on Environment in China in 2013. Beijing: China Environment Press.

571 Ministry of Environmental Protection of the People's Republic of China. 2014. Annual Statistic 572 Report on Environment in China in 2014. Beijing: China Environment Press. 


\section{Table 1 (on next page)}

Emission limits for wastewater pollutants in the textile industry. 


\begin{tabular}{cc}
\hline Limits of Pollutant Species & Limits \\
\hline $\mathrm{pH}$ & $6-9$ \\
$\mathrm{COD}_{\mathrm{Cr}}$ & 100 \\
$\mathrm{BOD}_{5}$ & 25 \\
Suspended matter & 60 \\
Chroma & 70 \\
Aniline & 1.0 \\
Total nitrogen & 20 \\
Total phosphorus & 1.0 \\
ClO & 0.5 \\
Organic halogen & 15 \\
Sulfide & 1.0 \\
Ammonia nitrogen & 12 \\
Hexavalent chromium & 0.5 \\
\hline
\end{tabular}

1 
Figure 1

\section{Decoupling standard of Decoupling Elasticity Method}

The decoupling state is divided into eight types. Figure 1 shows that strong decoupling is the most ideal state of sustainable development, followed by weak decoupling. In addition, the other states are all not ideal, and the strong and negative decoupling is the most unsatisfactory state.

Strong negative decoupling $\triangle V O L>0, \triangle G D P<0$

$D_{V O L-G D P} \in(-\infty, 0)$

$\triangle V O L_{\uparrow}$ Expansive negative

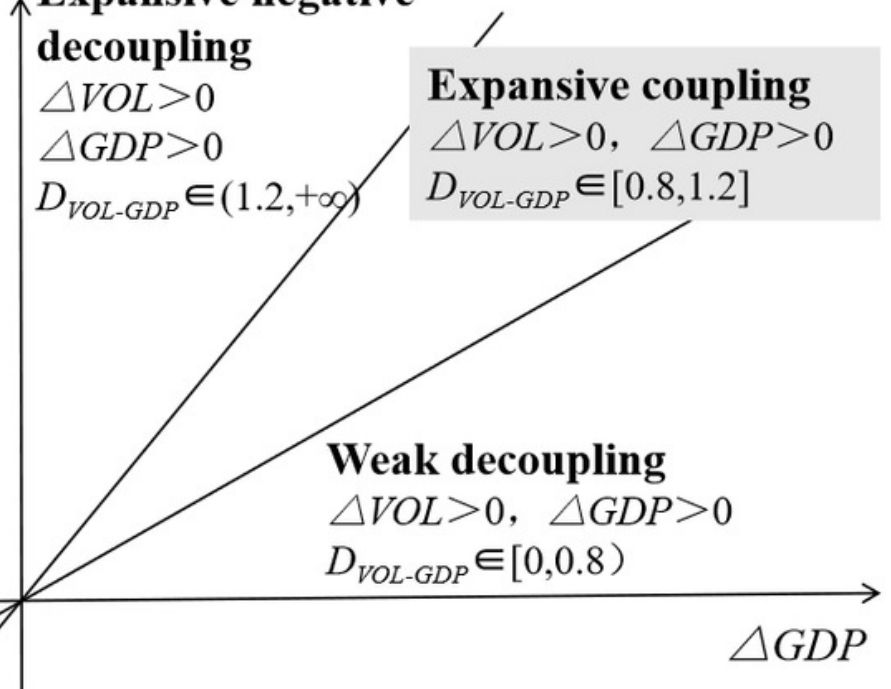

Weak negative decoupling $\triangle V O L<0, \triangle G D P<0$

$D_{\text {VOL-GDP }} \in[0,0.8)$

\section{Recessive coupling}

$\triangle V O L<0, \quad \triangle G D P<0$

$D_{V O L-G D P} \in[0.8,1.2]$

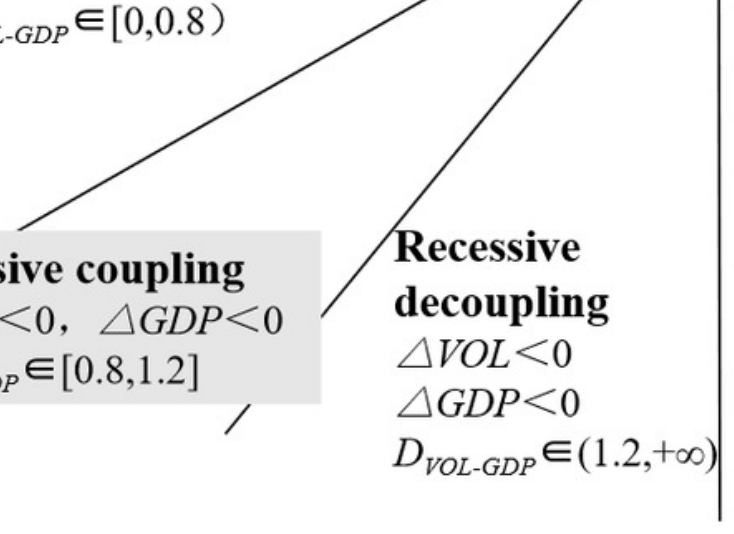

Strong decoupling

$\triangle V O L<0, \quad \triangle G D P>0$

$D_{\text {VOL-GDP }} \in(-\infty, 0)$ 
Table 2 (on next page)

Standard of Double Decoupling Degree of Water Consumption and Wastewater Discharge in the Textile Industry 


\begin{tabular}{|c|c|c|c|}
\hline \multirow{2}{*}{$\begin{array}{l}\text { Decoupling } \\
\text { degree }\end{array}$} & \multirow{2}{*}{$\begin{array}{l}\text { Relationship between water } \\
\text { footprint and economic growth }\end{array}$} & \multicolumn{2}{|c|}{ Evaluation value of decoupling status } \\
\hline & & $\begin{array}{l}\text { Elasticity } \\
\text { coefficient }\end{array}$ & $\begin{array}{l}\text { Decoupling } \\
\text { index } \\
\end{array}$ \\
\hline \multirow{4}{*}{$\begin{array}{c}\text { Strong } \\
\text { decoupling }\end{array}$} & \multirow{4}{*}{$\begin{array}{c}\Delta W F<0, \Delta \mathrm{G}>0 \\
D_{G-W F} \in(-\infty, 0)\end{array}$} & $(-\infty,-0.6)$ & 28 \\
\hline & & {$[-0.6,-0.4)$} & 27 \\
\hline & & {$[-0.4,-0.2)$} & 26 \\
\hline & & {$[-0.2,0)$} & 25 \\
\hline \multirow{4}{*}{$\begin{array}{c}\text { Weak } \\
\text { decoupling }\end{array}$} & \multirow{4}{*}{$\begin{array}{c}\Delta W F>0, \Delta G>0 \\
D_{G-W F} \in[0,0.8)\end{array}$} & {$[0,0.2)$} & 24 \\
\hline & & {$[0.2,0.4)$} & 23 \\
\hline & & {$[0.4,0.6)$} & 22 \\
\hline & & {$[0.6,0.8)$} & 21 \\
\hline \multirow{4}{*}{$\begin{array}{c}\text { Recessive } \\
\text { decoupling }\end{array}$} & \multirow{4}{*}{$\begin{array}{c}\Delta W F<0, \Delta G<0 \\
D_{G-W F} \in(1.2,+\infty)\end{array}$} & $(1.8,+\infty)$ & 20 \\
\hline & & $(1.6,1.8]$ & 19 \\
\hline & & $(1.4,1.6]$ & 18 \\
\hline & & $(1.2,1.4]$ & 17 \\
\hline \multirow{2}{*}{$\begin{array}{l}\text { Expansive } \\
\text { coupling }\end{array}$} & $\Delta W F>0, \Delta G>0$ & {$[0.8,1.0)$} & 16 \\
\hline & $D_{G-W F} \in[0.8,1.2]$ & {$[1.0,1.2]$} & 15 \\
\hline \multirow{2}{*}{$\begin{array}{l}\text { Recessive } \\
\text { coupling }\end{array}$} & $\Delta W F<0, \Delta G<0$ & {$[1.0,1.2]$} & 14 \\
\hline & $D_{G-W F} \in[0.8,1.2]$ & {$[0.8,1.0)$} & 13 \\
\hline \multirow{4}{*}{$\begin{array}{c}\text { Expansive } \\
\text { negative } \\
\text { decoupling }\end{array}$} & \multirow{4}{*}{$\begin{array}{c}\Delta W F>0, \Delta G>0 \\
D_{G-W F} \in(1.2,+\infty)\end{array}$} & $(1.2,1.4]$ & 12 \\
\hline & & $(1.4,1.6]$ & 11 \\
\hline & & $(1.6,1.8]$ & 10 \\
\hline & & $(1.8,+\infty)$ & 9 \\
\hline \multirow{4}{*}{$\begin{array}{c}\text { Weak } \\
\text { negative } \\
\text { decoupling }\end{array}$} & \multirow{4}{*}{$\begin{array}{c}\Delta W F<0, \Delta G<0, \\
D_{G-W F} \in[0,0.8)\end{array}$} & {$[0.6,0.8)$} & 8 \\
\hline & & {$[0.4,0.6)$} & 7 \\
\hline & & {$[0.2,0.4)$} & 6 \\
\hline & & {$[0,0.2)$} & 5 \\
\hline \multirow{4}{*}{$\begin{array}{c}\text { Strong } \\
\text { negative } \\
\text { decoupling }\end{array}$} & \multirow{4}{*}{$\begin{array}{r}\Delta W F>0, \Delta G<0 \\
D_{G-W F} \in(-\infty, 0)\end{array}$} & {$[-0.2,0)$} & 4 \\
\hline & & {$[-0.4,-0.2)$} & 3 \\
\hline & & {$[-0.6,-0.4)$} & 2 \\
\hline & & $(-\infty,-0.6)$ & 1 \\
\hline
\end{tabular}




\section{Table 3 (on next page)}

Decoupling Elasticity Index of Water Resources Consumption in China's Textile Industry from 2002 to 2015 


\begin{tabular}{ccccc}
\hline Year & $\mathbf{\%} \boldsymbol{\Delta} \boldsymbol{W C}$ & $\mathbf{\%} \boldsymbol{\Delta} \boldsymbol{G}$ & $\boldsymbol{D}_{\boldsymbol{G}-\boldsymbol{W C}}$ & Degree of Decoupling \\
\hline 2002 & 14.23 & 7.15 & 1.99 & Expansive negative decoupling \\
2003 & -10.11 & 7.66 & -1.32 & Strong decoupling \\
2004 & 18.79 & 18.67 & 1.01 & Expansive coupling \\
2005 & 15.01 & 22.86 & 0.66 & Weak decoupling \\
2006 & -2.79 & 26.64 & -0.10 & Strong decoupling \\
2007 & 10.28 & 18.85 & 0.55 & Weak decoupling \\
2008 & -1.72 & 40.73 & -0.04 & Strong decoupling \\
2009 & -0.34 & 6.38 & -0.05 & Strong decoupling \\
2010 & 2.43 & 12.40 & 0.20 & Weak decoupling \\
2011 & -16.59 & 25.39 & -0.65 & Strong decoupling \\
2012 & 2.12 & -3.09 & -0.69 & Strong negative decoupling \\
2013 & -2.56 & 4.84 & -0.53 & Strong decoupling \\
2014 & 10.10 & 0.75 & 13.47 & Expansive negative decoupling \\
2015 & -1.84 & 7.42 & -0.25 & Strong decoupling \\
\hline
\end{tabular}

1 


\section{Table 4 (on next page)}

Decoupling Elasticity of Grey Water Footprint in China Textile Industry from 2002 to 2015 


\begin{tabular}{ccccc}
\hline Year & $\boldsymbol{\%} \boldsymbol{\Delta} \boldsymbol{W} \boldsymbol{F}_{\boldsymbol{g}}$ & $\boldsymbol{\%} \boldsymbol{\Delta} \boldsymbol{G}$ & $\boldsymbol{D}_{\boldsymbol{G}-\boldsymbol{W F g}}$ & Degree of Decoupling \\
\hline 2002 & $-5.99 \%$ & $7.15 \%$ & -0.84 & Strong decoupling \\
2003 & $-5.81 \%$ & $7.66 \%$ & -0.76 & Strong decoupling \\
2004 & $13.58 \%$ & $18.67 \%$ & 0.73 & Weak decoupling \\
2005 & $4.01 \%$ & $22.86 \%$ & 0.18 & Weak decoupling \\
2006 & $5.55 \%$ & $26.64 \%$ & 0.21 & Weak decoupling \\
2007 & $3.04 \%$ & $18.85 \%$ & 0.16 & Weak decoupling \\
2008 & $-5.90 \%$ & $40.73 \%$ & -0.14 & Strong decoupling \\
2009 & $4.13 \%$ & $6.38 \%$ & 0.65 & Weak decoupling \\
2010 & $-2.90 \%$ & $12.40 \%$ & -0.23 & Strong decoupling \\
2011 & $5.13 \%$ & $25.39 \%$ & 0.20 & Weak decoupling \\
2012 & $-4.56 \%$ & $-3.09 \%$ & 1.48 & Recessive decoupling \\
2013 & $-2.60 \%$ & $4.84 \%$ & -0.54 & Strong decoupling \\
2014 & $-7.29 \%$ & $0.75 \%$ & -9.72 & Strong decoupling \\
2015 & $-6.85 \%$ & $7.42 \%$ & -0.92 & Strong decoupling \\
\hline
\end{tabular}

1 


\section{Table 5 (on next page)}

Decoupling elasticity of water resources environment and economic growth in China's textile industry from 2002 to 2015 


\begin{tabular}{ccccc}
\hline Year & $\boldsymbol{\%} \boldsymbol{\Delta} \boldsymbol{W} \boldsymbol{F}$ & $\boldsymbol{\%} \boldsymbol{\Delta} \boldsymbol{G}$ & $\boldsymbol{D}_{\boldsymbol{G}-\boldsymbol{W F}}$ & Degrees of Decoupling/Coupling \\
\hline 2002 & $6.29 \%$ & $7.15 \%$ & 0.88 & Expansive coupling \\
2003 & $-8.61 \%$ & $7.66 \%$ & -1.12 & Strong decoupling \\
2004 & $16.93 \%$ & $18.67 \%$ & 0.91 & Expansive coupling \\
2005 & $11.18 \%$ & $22.86 \%$ & 0.49 & Weak decoupling \\
2006 & $-0.08 \%$ & $26.64 \%$ & -0.003 & Strong decoupling \\
2007 & $7.79 \%$ & $18.85 \%$ & 0.41 & Weak decoupling \\
2008 & $-3.09 \%$ & $40.73 \%$ & -0.08 & Strong decoupling \\
2009 & $1.09 \%$ & $6.38 \%$ & 0.17 & Weak decoupling \\
2010 & $0.68 \%$ & $12.40 \%$ & 0.05 & Weak decoupling \\
2011 & $-9.71 \%$ & $25.39 \%$ & -0.38 & Strong decoupling \\
2012 & $-0.35 \%$ & $-3.09 \%$ & 0.11 & Weak negative decoupling \\
2013 & $-2.58 \%$ & $4.84 \%$ & -0.53 & Strong decoupling \\
2014 & $3.96 \%$ & $0.75 \%$ & 5.28 & Expansive negative decoupling \\
2015 & $-3.42 \%$ & $7.42 \%$ & -0.46 & Strong decoupling \\
\hline
\end{tabular}


Table 6(on next page)

Absolute number comparison of decoupling years 


\begin{tabular}{|c|c|c|c|c|c|c|c|c|}
\hline \multicolumn{3}{|c|}{$\begin{array}{l}\text { Water consumption } \\
\text { decoupling }\end{array}$} & \multicolumn{3}{|c|}{$\begin{array}{c}\text { Wastewater discharge } \\
\text { decoupling }\end{array}$} & \multicolumn{3}{|c|}{$\begin{array}{c}\text { Double decoupling of } \\
\text { water consumption and } \\
\text { wastewater discharge }\end{array}$} \\
\hline $\begin{array}{c}\text { Degrees of } \\
\text { Decoupling/Coupling }\end{array}$ & Year & $\begin{array}{c}\text { Elasticity } \\
\text { Coefficient }\end{array}$ & $\begin{array}{c}\text { Degrees of } \\
\text { Decoupling/Coupling }\end{array}$ & Year & $\begin{array}{r}\text { Elasticity } \\
\text { Coefficient }\end{array}$ & $\begin{array}{c}\text { Degrees of } \\
\text { Decoupling/Coupling }\end{array}$ & Year & $\begin{array}{l}\text { Elasticity } \\
\text { Coefficient }\end{array}$ \\
\hline Strong decoupling & 2003 & -1.32 & Strong decoupling & 2002 & -0.84 & Strong decoupling & 2003 & -1.12 \\
\hline Strong decoupling & 2006 & -0.1 & Strong decoupling & 2003 & -0.76 & Strong decoupling & 2006 & -0.003 \\
\hline Strong decoupling & 2008 & -0.04 & Strong decoupling & 2008 & -0.14 & Strong decoupling & 2008 & -0.08 \\
\hline Strong decoupling & 2009 & -0.05 & Strong decoupling & 2010 & -0.23 & Strong decoupling & 2011 & -0.38 \\
\hline Strong decoupling & 2011 & -0.65 & Strong decoupling & 2013 & -0.54 & Strong decoupling & 2013 & -0.53 \\
\hline Strong decoupling & 2013 & -0.53 & Strong decoupling & 2014 & -9.72 & Strong decoupling & 2015 & -0.46 \\
\hline Strong decoupling & 2015 & -0.25 & Strong decoupling & 2015 & -0.92 & Weak decoupling & 2005 & 0.49 \\
\hline Weak decoupling & 2005 & 0.66 & Weak decoupling & 2004 & 0.73 & Weak decoupling & 2007 & 0.41 \\
\hline Weak decoupling & 2007 & 0.55 & Weak decoupling & 2005 & 0.18 & Weak decoupling & 2009 & 0.17 \\
\hline Weak decoupling & 2010 & 0.2 & Weak decoupling & 2006 & 0.21 & weak decoupling & 2010 & 0.05 \\
\hline $\begin{array}{l}\text { expansive negative } \\
\text { decoupling }\end{array}$ & 2002 & 1.99 & Weak decoupling & 2007 & 0.16 & expansive coupling & 2002 & 0.88 \\
\hline expansive coupling & 2004 & 1.01 & Weak decoupling & 2009 & 0.65 & expansive coupling & 2004 & 0.91 \\
\hline $\begin{array}{l}\text { Strong negative } \\
\text { decoupling }\end{array}$ & 2012 & -0.69 & Weak decoupling & 2011 & 0.2 & $\begin{array}{c}\text { weak negative } \\
\text { decoupling }\end{array}$ & 2012 & 0.11 \\
\hline $\begin{array}{c}\text { expansive negative } \\
\text { decoupling }\end{array}$ & 2014 & 13.45 & Recessive decoupling & 2012 & 1.48 & $\begin{array}{l}\text { expansive negative } \\
\text { decoupling }\end{array}$ & 2014 & 5.27 \\
\hline
\end{tabular}




\section{Figure 2}

\section{Decoupling index comparison}

In terms of the number of years to achieve strong decoupling, $t$ he total number of decoupling indices for strong decoupling years in water consumption decoupling is 184 . The total number of decoupling indices for strong decoupling years in wastewater discharge decoupling is 190 . T he total number of decoupling indices for strong decoupling years in double decoupling of water consumption and wastewater discharge is only 158 , which is much lower than the other two decoupling types. Combined with the situation of the weak decoupling year $s$, the sum of the strong and the weak decoupling indices of the double decoupling of water consumption and wastewater discharge is the lowest, only 249 .The sum of the strong and weak decoupling indices of water consumption decoupling and wastewater discharge decoupling reached 250 and 325 , respectively. The result shows that despite the optimistic results on the number of years necessary for the textile industry to achieve double decoupling of water consumption and wastewater discharge, its decoupling index is not ideal within the decoupling range.

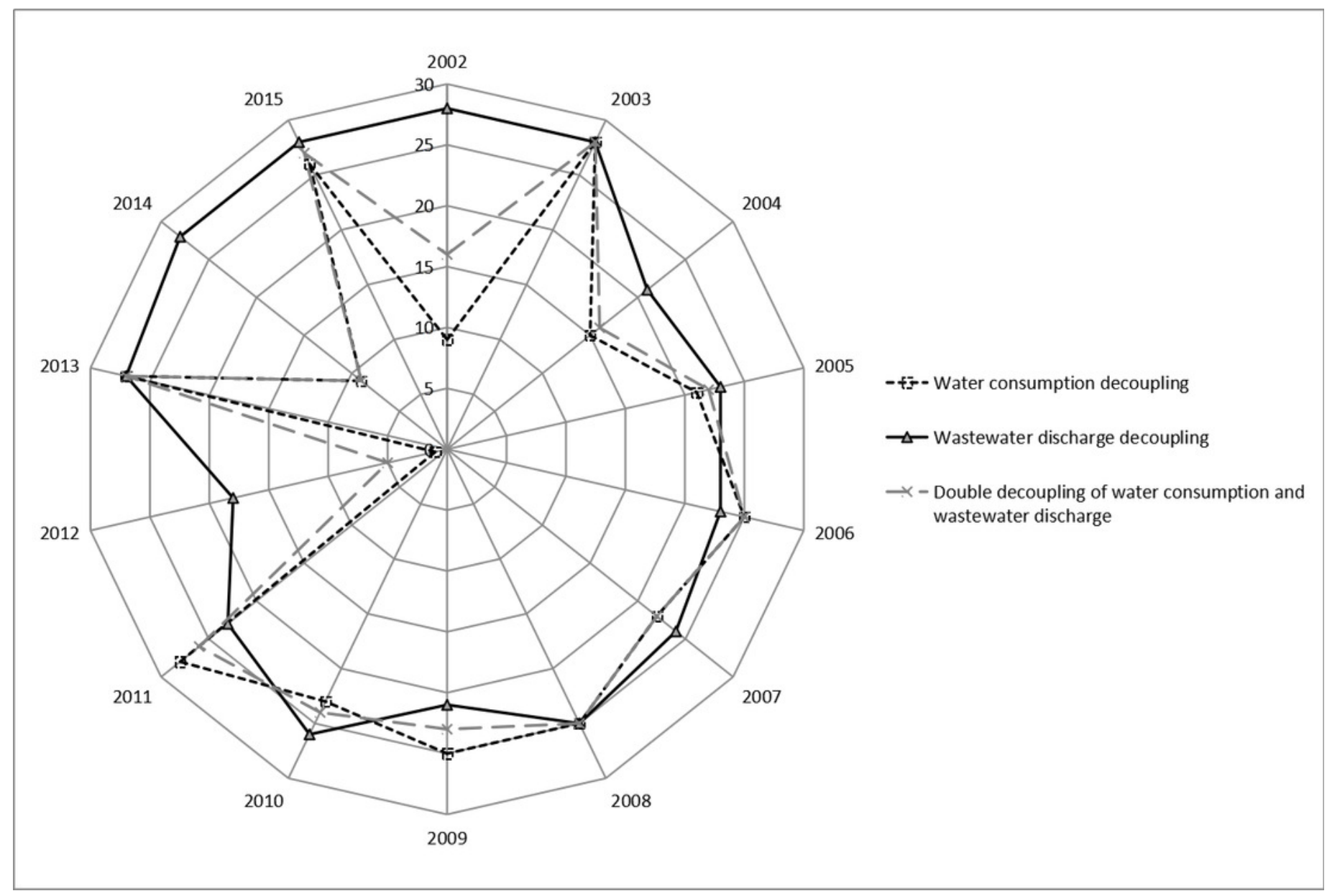

